\title{
Screening for Crop Response to Diazotrophic Bacteria Isolated from Potato Rhizosphere
}

\author{
A.P. Henagamage ${ }^{1, *}$, G. Seneviratne ${ }^{2}$, C.Abayasekera ${ }^{3}$ and K.M.S. Kodikara ${ }^{4}$ \\ ${ }^{1}$ Uva Wellassa University, Badulla, Sri Lanka \\ ${ }^{2}$ National Institute of Fundamental Studies, Kandy, Sri Lanka. \\ ${ }^{3}$ Department of Botany, Faculty of Science, University of Peradeniya, Sri Lanka \\ ${ }^{4}$ Regional Agriculture Research and Development Center, Bandarawela, Sri Lanka
}

\begin{abstract}
Microbe-plant interactions in the rhizosphere can be beneficial, neutral, or deleterious for plant growth. The present study aimed to characterize eight diazotrophic bacteria isolated from potato rhizosphere and to evaluate their effects on potato growth responses. Initially, soil bacterial isolates were screened for in vitro $\mathrm{pH}$, nitrogenase activity, in vitro IAA production and seedling vigor. Then, they were further evaluated for their effects on growth responses of potato seed tubers using a pot experiment under greenhouse conditions. Out of the bacterial isolates, Bacillus sp., Acidomonas sp., Serratia sp. and Bradyrhizobium sp. responded positively to all screening and greenhouse experiments. The highest nitrogenase activity, IAA production, seedling vigor and the lowest medium $\mathrm{pH}$ were shown by Bradyrhizobium sp. $(\mathrm{P}<0.05)$. Further, inoculation of potato with Bradyrhizobium sp. produced the highest tuber weight, tuber number and stolon number. Inoculum $\mathrm{pH}$ was inversely proportional to the production of IAA. Further, tuber weight and tuber number were increased with the reduction of soil $\mathrm{pH}$. Positive relationships were observed between IAA production with seedling vigor, tuber weight, and tuber number, separately. Out of the bacterial isolates, Bradyrhizobium sp. was found to be the best since it showed the highest performance in all screening and pot experiments.
\end{abstract}

Keywords: biofertilizers, plant growth promoting rhizobacteria, potato, rhizosphere microbes.

\section{INTRODUCTION}

The diverse groups of living microorganisms in soil can be named collectively as the 'soil microbiome'. Soil contains many microhabitats that are suitable for microbial growth. Microbes are aggregated in the immediate surroundings of plant roots, which is an active region for root activity and metabolism, and known as the 'rhizosphere' (Saharan and Nehra, 2011). Plant- associated bacteria that are able to colonize roots are called rhizobacteria and can be classified into beneficial, deleterious, and neutral groups on the basis of their effects on plant growth. Rhizobacteria, expressing direct or indirect beneficial responses in soil nutrient enhancement and plant growth, are classified as plant growth promoting rhizobacteria (PGPRs, Hayat et al., 2010). The direct plant growth promotion by PGPR entails either providing the plant with plant growth promoting substances that are synthesized by the bacterium or facilitating the uptake of certain plant nutrients from the environment. The indirect promotion of plant growth occurs when PGPR minimize or prevent deleterious effects of one or more phytopathogenic micro-organisms and help plants to withstand against environmental stresses (Glick et al., 2007). The use of PGPRs has been found to be beneficial in sustainable crop production (Dashti et al., 1997: Hayat et al., 2010). Therefore, PGPRs are now being used as microbial inoculants or biofertilizers to enhance crop productivity and to reduce the use of chemical fertilizers (CF) in agriculture (Adesemoye et al., 2009; Buddhika et al., 2014). In this regard, indigenous PGPRs in soil are preferred since they are completely adapted to the environment and can be more competitive than introduced microbial inoculants (Hayat et al., 2010). Beneficial microbial inoculants of PGPRs have been used in different leguminous and non-leguminous crops for several decades (Bashan, 1998; Adesemoye et al., 2009). Enhanced PGPRs activity in the rhizosphere exerts beneficial effects on plants either symbiotically or non-symbiotically. It has been reported that $1-4 \%$ of microorganisms isolated 
from naturally existing potato rhizosphere showed significant plant growth promotion on potato i.e. enhancement of the stolon length, early tuber setting and increase of tuber yield (Suslow et al., 1979). Application of PGPR strains have been reported to improve $\mathrm{N}$ availability through the fixation of atmospheric nitrogen $\left(\mathrm{N}_{2}\right)$ (Seneviratne et al., 2008: Franche et al., 2009) in soil and solublization of minerals (Kloepper, 1997; Glick, 2007) while enhancing crop productivity of other non-leguminous tuber crops such as sweet potato (Ipomoea batatas) (Yasmin et al., 2009).

In addition to $\mathrm{N}_{2}$ fixation, PGPRs enhance seed germination, seedling vigor and ultimately plant growth due to the production of plant growth hormones (Kumar et al., 2012). Generally, IAA has been reported to stimulate plant growth. It is one of the most important phytohormones and function as an important signal molecule in the regulation of growth promotion (Hayat et al., 2010). Production of IAA by microbial isolates varies greatly among different species and strains (Ngoma et al., 2012). For example, Azospirillum sp., a diazotroph enhanced plant growth through its ability to produce a high amount of IAA (Shahab et al., 2009). Further, the inductive role of IAA on stolon initiation and tuber induction in potato has been documented in previous studies (Dragicevic et al., 2008). Therefore, prior characterization of beneficial effects of naturally existing rhizosphere microbial isolates is of great importance. This study was aimed at screening and characterizing the functions of beneficial microbial strains isolated from potato rhizosphere to evaluate their effects on crop responses.

\section{METHODS AND MATERIALS}

\section{Isolation of rhizosphere microorganisms}

Soil samples and plant specimens (Solanum tuberosum L.) were collected from a cultivated crop land at the Regional Agriculture Research and Development Center, Bandarawela, $\left(6^{\circ} 48^{\prime}\right.$ $0 " \mathrm{~N}, 80^{\circ} 58^{\prime} 0^{\prime \prime}$ E) [up country intermediate zone, $\mathrm{IU}_{3}$, elevation 1,506 asl, temperature $22{ }^{\circ} \mathrm{C}$, and annual rainfall $1,100 \mathrm{~mm}-1,400 \mathrm{~mm}]$, Sri Lanka. These were transported to the laboratory of the National Institute of Fundamental Studies, Kandy, Sri Lanka. Root associated microorganisms were isolated using streak and spread plate techniques and soil microorganisms were isolated using soil dilution plate technique. The soil samples were serially diluted (10 fold) and inoculated on sterile Nutrient Agar [NA, (Himedia $^{\mathrm{TM}}$, India) $20 \mathrm{~g}$ per liter of medium] plates followed by incubation for $24 \mathrm{hrs}$ at $25^{\circ} \mathrm{C}$. Bacterial colonies were differentiated on the basis of colony morphology. Colonies were sub cultured on the NA medium and re-incubated at $25^{\circ} \mathrm{C}$ for $48-72 \mathrm{hrs}$. This isolation process was repeated until monocultures were obtained. Isolated bacteria were identified based on preliminary biochemical tests (Gram's test, Catalase test, Oxidase test, Citrate test, Urease test, MR-VP test, Indole test and Motility test).

\section{Screening of microbial isolates}

Diazotrophic microorganisms were isolated using Combine Carbon Medium (CCM, Koomnok et al., 2007), a modified $\mathrm{N}$ free medium for $\mathrm{N}_{2}$ fixing microorganisms ( $\mathrm{pH}$ 6.8). Several screening experiments were carried out for the diazotrophic bacterial isolates as follows. Bacterial isolates were inoculated in $10 \mathrm{ml}$ of $\mathrm{CCM}$ broth and incubated for five days at $25^{\circ} \mathrm{C}$. Thereafter, pHs of broth media with different microbial inoculations were measured. Lettuce seed germination assay was used to examine pathogenecity and toxicity, and also the response of early plant growth to the isolates since lettuce is generally a highly responsive crop to environmental cues (Argyris et al., 2008). Lettuce seeds were treated separately by each microbial broth cultures under aseptic conditions (Mia et al., 2012). Then, they were allowed to germinate in the dark for five days and seedling vigor was calculated using germination percentage, and root and shoot lengths. Nitrogenase activity of the microbial isolates was measured using the acetylene reduction assay (Husen, 2003; Piromyou et al., 2011). Production of IAA by the microbial isolates was measured colorimetrically using Salkowski regent (Husen, 2003; Shahab et al., 2009; Buddhika et al., 2014). Selected bacterial isolates were evaluated for their growth responses on potato using a pot experiment under greenhouse conditions.

\section{Evaluation of screened microbial inoculants for growth responses in potato}

Plant growth effects and pathogenicity of the isolated microbial cultures were evaluated using a pot experiment with potato seed tubers at the Regional Agriculture Research and Development Center, Bandarawela, Sri Lanka. Effect on 
growth was evaluated using tuber fresh weight, tuber number, stolon number, shoot dry weight and root dry weight of potato plants. The emergence of bacterial wilt disease and late blight disease were evaluated using number of wilted plants and number of leaves with brown/black lesions, respectively. Heat sterilized (dry oven at $160{ }^{\circ} \mathrm{C}$ for $2 \mathrm{hrs}$ ) loamy soil was used (particle size $\leq 2 \mathrm{~mm}$ ) as the growth medium. Disease free potato seed tubers ('Granola' variety) were sown in black plastic pots (pot size- 6 inch diameter) with the sterilized growth medium. Five replicates were maintained for each treatment and the pots were arranged in complete randomized design (CRD) in the greenhouse. A mixture of urea $(3.0 \mathrm{~g})$, Triple Super Phosphate (TSP) $(5.0 \mathrm{~g})$ and Muriate of Potash (MOP) (2.0 g) was blended with the soil as the basal fertilizer mixture. Rate of the Chemical fertilizer (CF) application was calculated per plant basis according to the standard recommendations. After the establishment of the roots, $\mathrm{CF}$ mixture $(3.0 \mathrm{~g}$ of urea and $2.0 \mathrm{~g}$ of MOP) and $20 \mathrm{ml}$ of diluted diazoptrophic bacterial cultures in CCM broths $\left(10^{7} \mathrm{cfu} / \mathrm{ml}\right)$ were mixed separately with the soil medium. Potato plants applied with uninoculated CCM broth was taken as the control for the experiment. Moisture level of the potting medium was maintained constantly by applying $250 \mathrm{ml}$ of water for each pot every day. Plants were grown with a daily minimum-maximum temperature range of $20^{\circ} \mathrm{C}-30{ }^{\circ} \mathrm{C}$.

Visual observations were made of the plants once a week to evaluate the emergence of any harmful pest attacks or diseases. Number of wilted plants and leaves with brown/ black lesions were counted once in two weeks to evaluate the emergence of bacterial wilt or late blight diseases due to inoculation. Section cuttings of infected leaves were observed under the high power of light microscope to confirm the disease infections. Results were compared with non-treated control to evaluate pathogenicity. After 90 days from seed sowing, plant responses i.e. number of tubers, dry and fresh weights of the tubers, roots and shoots and number of stolons and soil $\mathrm{pH}$, were recorded.
Statistical data analyses were performed using one-way Analysis of Variance (ANOVA) in MINITAB 16 Statistical Software. Treatment means were compared using the Tukey's HSD test at 5\% probability level. A statistical ranking method for data on screening and plant growth response was used to select effective microbial strains. Relationships between different parameters were established using non-linear regression analysis.

\section{RESULTS}

\section{Isolation, identification and preliminary screening of microbial monocultures}

Fourteen bacterial strains were isolated initially from the rhizosphere of potato. Out of them, eight isolates were diazotrophic bacteria and identified as Acinetobacter sp., Bacillus sp. (two species; sp. 1 and 2), Acidomonas sp., Pseudomonas sp. (two species; sp. 1 and 2), Serratia sp. and Bradyrhizobium sp. All bacterial isolates, except Acinetobacter sp. and Pseudomonas sp., showed acidic $\mathrm{pH}$ in CCM (Fig. 1a). Out of eight different strains, the lowest $\mathrm{pH}(\mathrm{P}<0.05)$ and the highest nitrogenase activity $(\mathrm{P}<0.05)$ were recorded by Bradyrhizobium sp. (Figures 1a and 1b). Acinetobacter sp. and Pseudomonas sp. showed very low nitrogenase activity compared to other isolates. The highest significant IAA production was shown by Bradyrhizobium sp. $(\mathrm{P}<0.05)$ compared to all other bacterial isolates (Fig. 1c). Moreover, out of eight different bacterial isolates, the highest significant seedling vigor value $(\mathrm{P}<0.05)$ was shown by Bradyrhizobium sp. (Figure 1d) and the seedling vigor was enhanced by approximately $35 \%$ compared to the un-inoculated control.

A significant negative correlation was observed $\left(\mathrm{R}^{2}=-0.78, \mathrm{P}=0.02\right)$ between $\mathrm{pH}$ and IAA production by different bacterial isolates (Figure 2a). Further, a significant positive correlation $\left(\mathrm{R}^{2}=0.94, \mathrm{P}=0.001\right)$ was observed between seedling vigor and IAA production (Figure 2b). Therefore, the correlations revealed the effect of IAA production on medium $\mathrm{pH}$ of the medium and the seedling growth. 


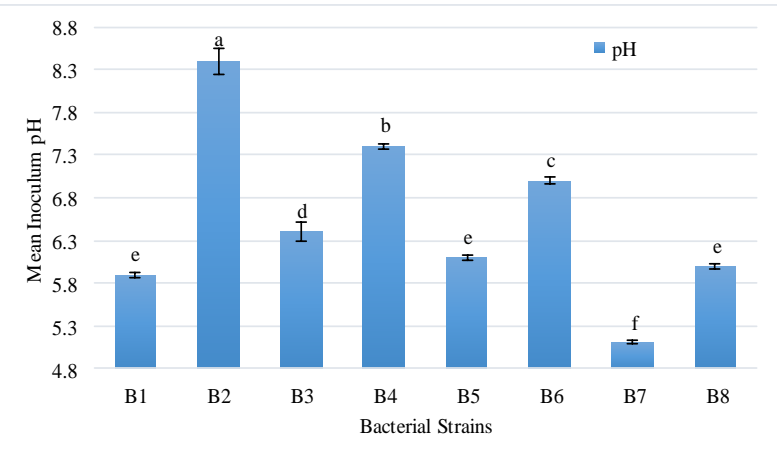

(a)

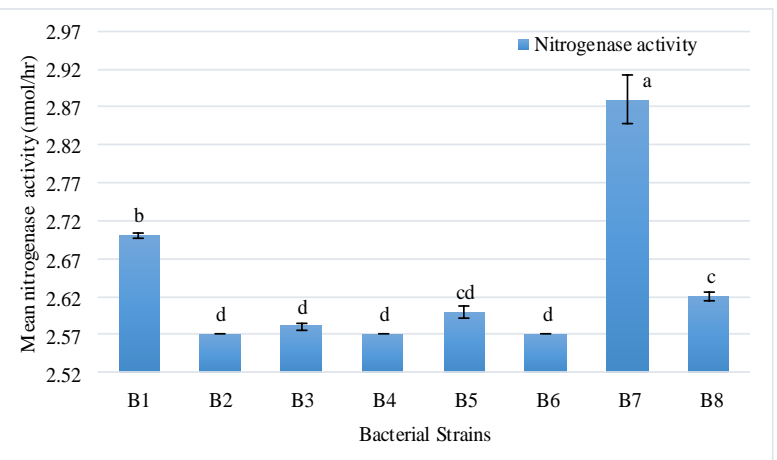

(b)

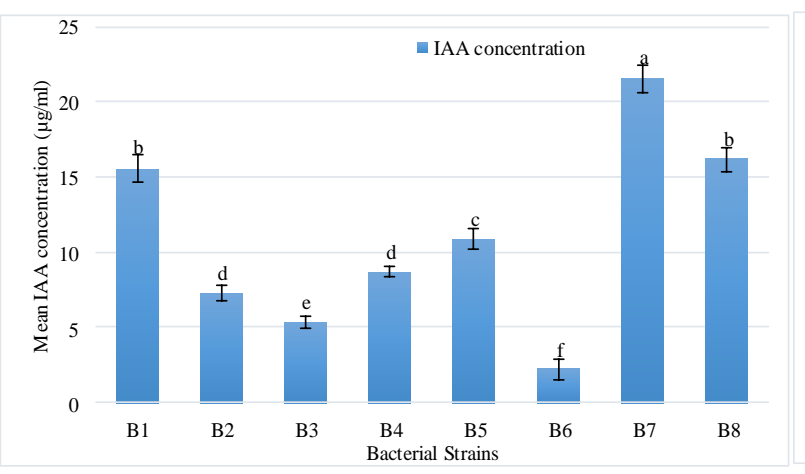

(c)

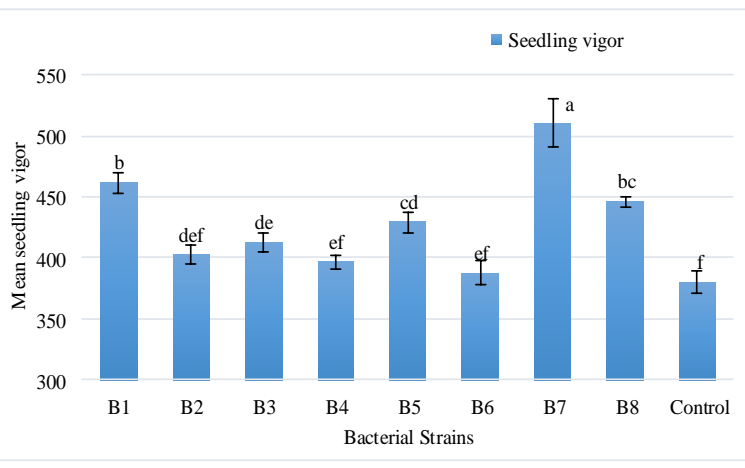

(d)

Figure 1: Responses of bacterial isolates to screening experiments. (a)- Broth medium pHs under different bacterial isolates. (b)- Nitrogenase activity based on ethylene production. (c)- IAA production by different bacterial isolates. (d)- Seedling vigor for lettuce seeds treated with different bacterial isolates (control - only ML medium). (B1 and B8- Bacillus sp., B2Acinetobacter sp., B3- Acidomonas sp., B4- and B6- Pseudomonas sp., B5- Serratia sp., B7- Bradyrhizobium sp.) Columns with the same letter are not significantly different at $5 \%$ probability level. Vertical bars show standard errors.

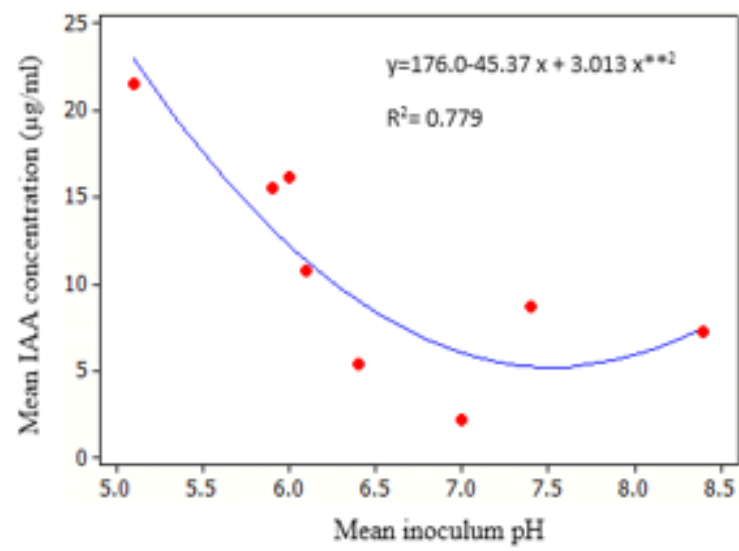

(a)

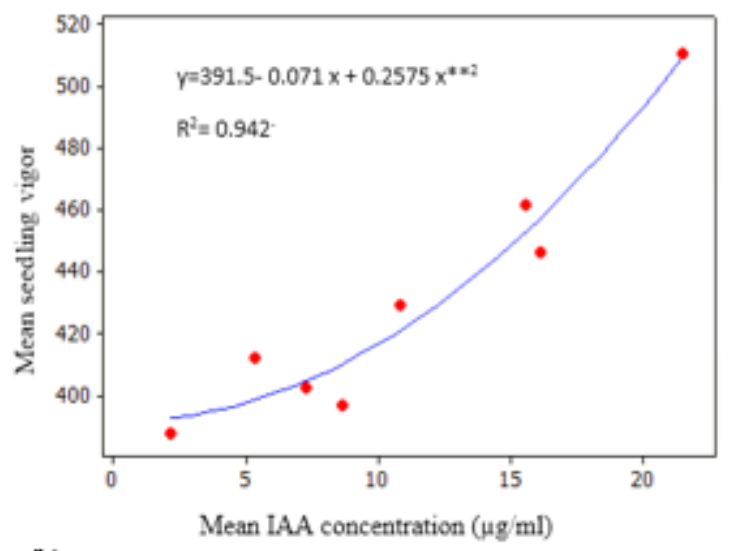

(b)

Figure 2: Correlations between different screening parameters. (a)- Non-Linear regression plot between mean ethylene production by different bacterial strains and mean inoculum $\mathrm{pH}$. (b)- Non-linear regression plot between mean seedling vigor and mean IAA production by different bacterial isolates. 
Evaluation of the effect of screened microbial isolates on potato tuber development

In comparison with all other treatments, the highest significant tuber weight $(\mathrm{P}<0.05)$ was shown by plants inoculated with Bradyrhizobium sp. (Figure 3a). All bacterial isolates, except Acinetobacter sp. and Pseudomonas sp., enhanced the tuber weight compared to nontreated control. The highest mean number of tubers $(4.2 \pm 0.45)$ and stolon $(3.2 \pm 0.84)$, and the lowest mean soil $\mathrm{pH}(5.28 \pm 0.12)$ were recorded with Bradyrhizobium sp. (Figures 3 b, c and d). Further, two sample t-test confirmed that Bradyrhizobium sp. significantly enhanced the mean number of tubers $(\mathrm{P}<0.05)$ and stolon $(\mathrm{P}$
$<0.05)$ compared to the non- treated control. All bacterial isolates did not significantly influence the shoot $(\mathrm{P}>0.05)$ and root dry weights $(\mathrm{P}>$ $0.05)$ of potato.

Significant negative relationships were observed between mean $\mathrm{pH}$ of soil and mean tuber weight (Figure 4a) $\left(\mathrm{R}^{2}=0.94, \mathrm{P}=0.00\right)$ and mean tuber number (Figure $4 \mathrm{~b})\left(\mathrm{R}^{2}=0.83, \mathrm{P}\right.$ $=0.00$ ). Figures $4 \mathrm{c}$ and $4 \mathrm{~d}$ showed significant positive relationships of IAA concentration against tuber weight $\left(R^{2}=0.76, P=0.03\right)$, and tuber number $\left(R^{2}=0.58, P=0.04\right)$. An enhanced tuberization was recorded with the application of selected microbial inoculants.

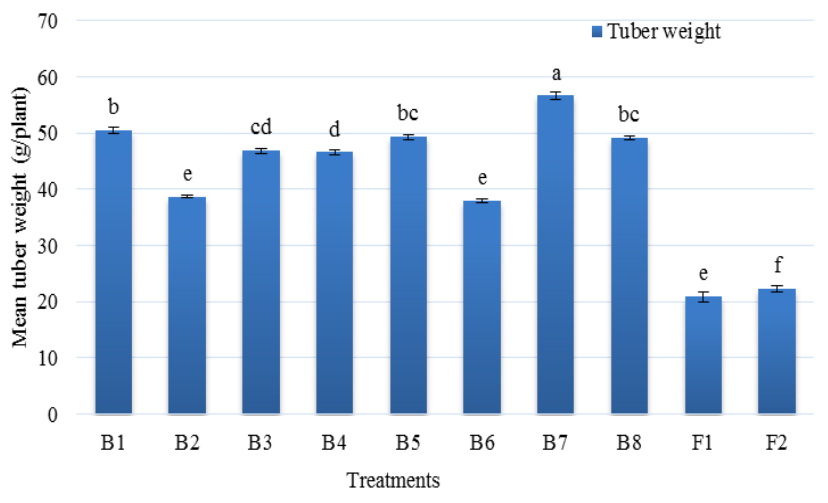

(a)

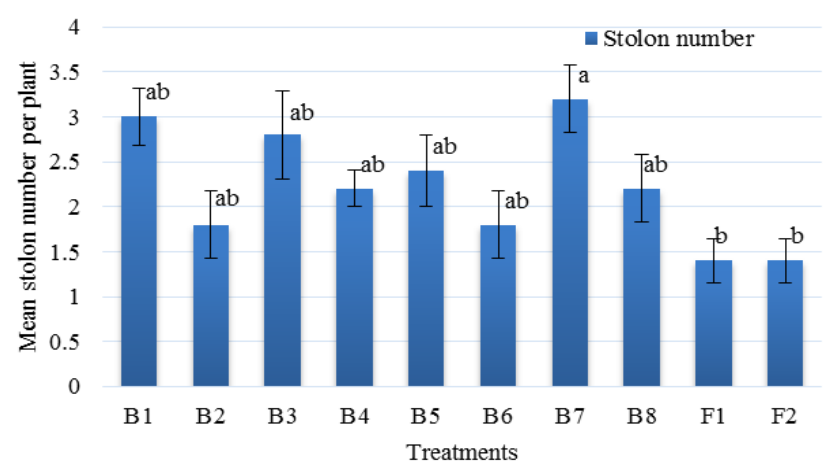

(c)

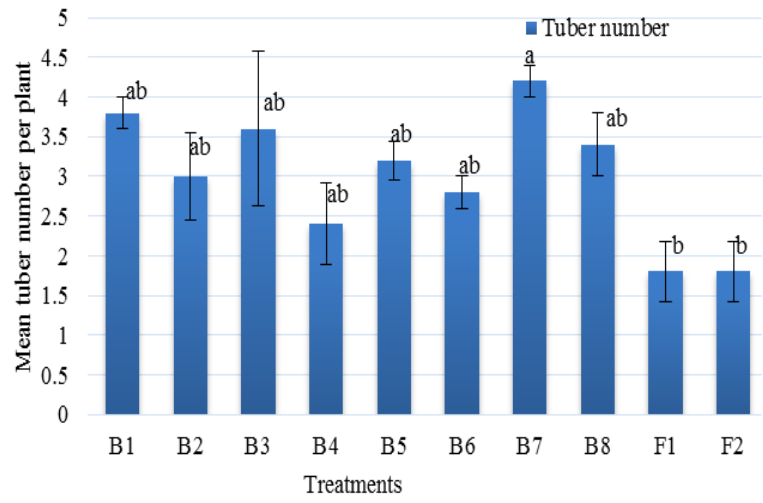

(b)

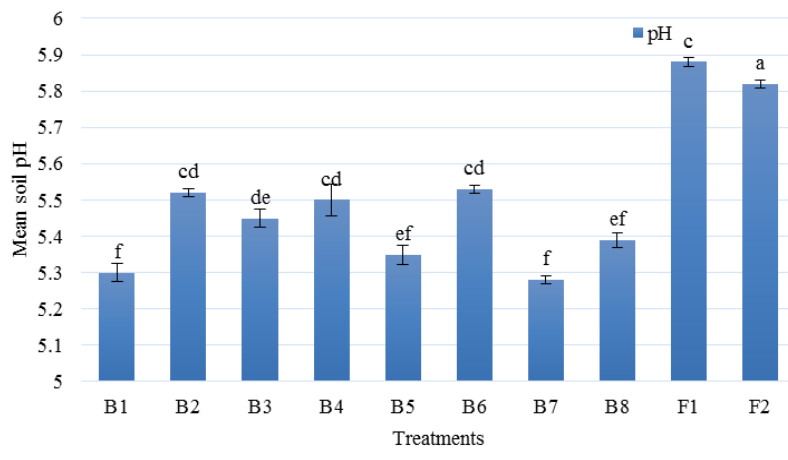

(d)

Figure 3: The effect of different microbial isolates on growth parameters of potato and soil $\mathrm{pH}$. (a) Mean weight of potato tubers for different treatments. (b) Mean tuber number for different treatments. (c) Mean stolon number for different treatments. (d) Mean soil pH for different treatments. B1 to B8- different bacterial isolates (B1 and B8- Bacillus sp., B2Acinetobacter sp., B3- Acidomonas sp., B4- and B6- Pseudomonas sp., B5- Serratia sp., B7- Bradyrhizobium sp.). Control only CCM. Columns with the same letter are not significantly different at $5 \%$ probability level. Vertical bars show standard errors. 


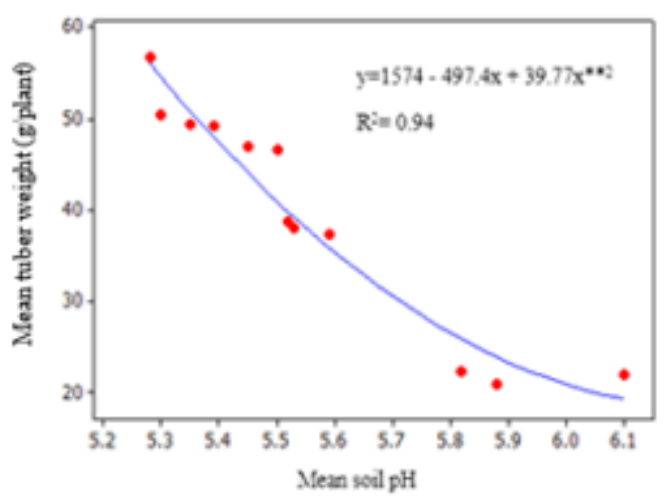

(a)

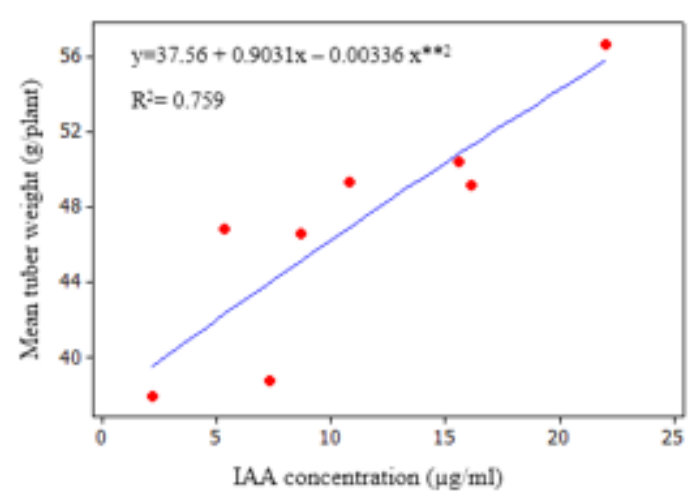

(c)

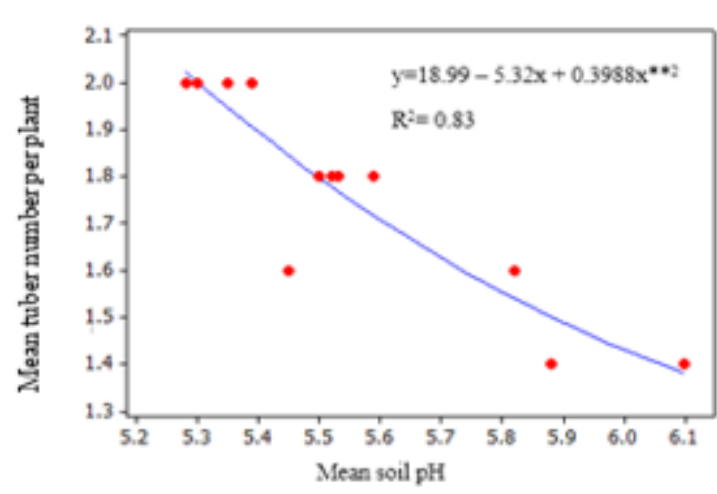

(b)

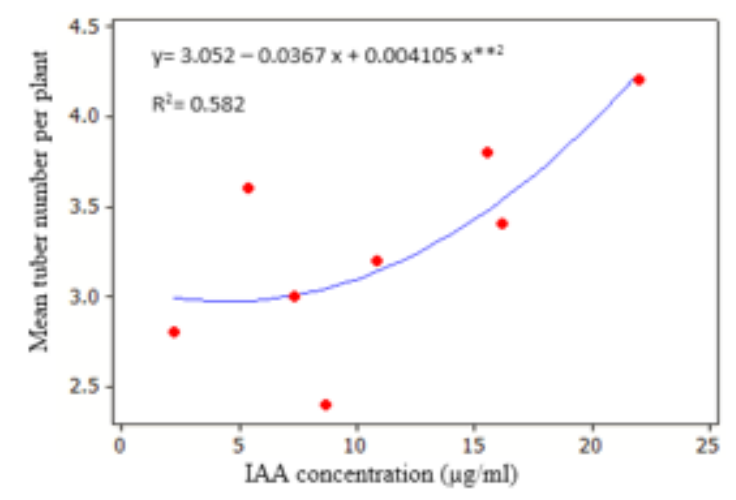

(d)

Figure 4: Non-linear regression relationships between (a) mean soil $\mathrm{pH}$ and mean potato tuber weight (b) the mean soil $\mathrm{pH}$ and mean tuber number (c) mean IAA concentration of bacterial inocula and mean potato tuber weight (d) the mean IAA concentration and mean tuber number when inoculated in a soil pot experiment.

\section{DISCUSSION}

Reduction of the $\mathrm{pH}$ of the medium was recorded by most of the microbial isolates. The microbial acidity is generally attributed to the production of plant growth promoting hormones like IAA (Shahab et al., 2009). However, reduction of $\mathrm{pH}$ in the growth medium can also be attributed to production of different organic and inorganic acids such as gluconic acid and 2-ketogluconic acid (Walpola and Yoon, 2012) by soil microorganisms. Production of chelating substances or inorganic acids such as sulphidric, nitric and carbonic acids may also contribute to the process (Vessey, 2003; Martinez-Viveros et al., 2010). Another in vitro study with some bacterial species showed a relationship among improved $\mathrm{N}_{2}$ fixation, high IAA production and decreased $\mathrm{pH}$ (Bianco and Defez, 2010).

Further, it has been reported by several other studies that the nitrogenase activities shown by PGPRs vary between $0.25 \mathrm{nmoles} / \mathrm{hr}$ to $15.8 \mathrm{nmoles} / \mathrm{hr}$ (Sloger and Berkum, 1988; Khan and Doty, 2009). However, most of the bacterial isolates in the current study showed moderate nitrogenase activity $(2.5-2.9 \mathrm{nmol} / \mathrm{hr})$ compared to the previous studies. Nitrogenase activity is considered as an indirect measurement of $\mathrm{N}_{2}$ fixation by the prokaryotes (Tissue et al., 1997). However, several studies have reported that PGPRs may simultaneously use mechanism besides biological $\mathrm{N}_{2}$ fixation such as producing phytohormones like IAA, cytokinins and gibberellins to enhance plant growth stimulation (Zahir et al., 2004; Van Loon, 2007; Bhattacharyya and Jha, 2012).

A diverse group of microbes, including soil, epiphytic and tissue colonizing bacteria synthesizes IAA and the production is greatly varied among soil bacterial species (Patten and Glick, 1996; Xie et al., 1996; Acuna et al., 2011). It has been reported that plant growth regulators like IAA can be produced by more 
than $80 \%$ of bacteria isolated from rhizosphere (Patten and Glick, 1996: Hayat et al., 2010). A study has shown that rhizobacteria isolated from sweet potato have the capability of producing $3.98-13.33 \mu \mathrm{g} / \mathrm{ml}$ IAA (Yasmin et al., 2009). However, most of the bacterial isolates in the current study showed higher IAA productions ranging between $2.2-21.54 \mu \mathrm{g} / \mathrm{ml}$ higher than that of microbial strains reported in the literature. A similar relationship between high IAA production and decreased medium $\mathrm{pH}$ has been reported by another study (Ameur and Ghoul, 2012). In concurrence with that, relationship between low $\mathrm{pH}$ environment and IAA production by the bacterial strains like Bacillus sp. and Paenibacillus sp., has also been reported (Acuna et al., 2011).

Moreover, beneficial soil microorganisms which produce different phytohormones, promote plant growth while increasing germination rate of seeds (Bhattacharyya and Jha, 2012). Evidences suggest that the enhancement of seedling vigor of plants and faster germination of seeds with the inoculation of beneficial rhizobacterial strains like Rhizobium sp. due to the production of different phytohormones including IAA (Mia et al., 2012). Further, it has been reported that the exogenous IAA produced by PGPRs enhance plant growth and development by regulating seedling vigor through stimulating root elongation and formation of lateral roots (Ahemad and Kibret, 2014).

It has been reported by previous studies that vegetative growth, tuber number and tuber yield can be enhanced (Nookaraju et al., 2011) by the inoculation of PGPRs with potato seed tubers before planting (Vrany and Fiker 1984; Sturz, 1995) in soil. It has been reported that beneficial microbial inocula like PGPRs in the soil solution near root hairs increase plant growth promotion through the secretion of plant growth promoters like IAA (Acuna et al., 2011). The application of exogenous IAA can acts as signaling molecule which can lead to early tuber initiation and tuber enlargement in potato (Harmey et al., 1966; Patten and Glick, 1996). The inductive role of IAA on stolon initiation and tuber induction in potato has been documented in a previous study (Dragicevic et al., 2008). Therefore, the high tuberization shown by Bradyrhizobium sp. inoculated potato in the present study may be due to cumulative effects of elevated IAA production and high nitrogenase activity (Figures 1c and 1b). Further, statistical ranking of the data obtained from screening and pot experiments confirmed the beneficial role of Bacillus sp., Acidomonas sp., Serratia sp. and Bradyrhizobium sp.

\section{CONCLUSIONS}

Out of the isolated bacterial species, Bacillus sp.,

Acidomonas sp., Serratia sp. and Bradyrhizobium sp. showed lower pHs and higher nitrogenase activities. , They also reported higher IAA production, seedling vigor and growth performance in greenhouse pot experiments with potato seed tubers. Therefore, they can be considered as beneficial PGPRs with the ability to stimulate tuberization in potato. Bradyrhizobium sp. showed the highest PGPRs activity in potato tuberization. Thus, Bradyrhizobium sp. can be considered as the best isolate to use as an inoculum to improve growth and tuberization in potato.

\section{ACKNOWLEDGEMENT}

National Science Foundation is acknowledged for funding the research (Grant No. $\mathrm{NSF} / \mathrm{SCH} / 2012 / 02$ ).

\section{REFERENCES}

Acuna, J.J., Jorquera, M.A., Martínez, O.A., Blackburn, D.M., Fernández, M.T., Marschner, P., Greiner, R. and Mora, M.L. (2011). Indole acetic acid and phytase activity produced byrhizosphere bacilli as affected by $\mathrm{pH}$ and metals. Journal of Soil Science and Plant Nutrition. 11 (3): 1-12.

Adesemoye, A.O., Torbert, H.A. and Kloepper, J.W. (2009). Plant growth-promoting rhizobacteriaallow reduced application rates of chemical fertilizers. Microbial Ecology. 58:921929.

Ahemad, M. and Kibret, M. (2014). Mechanisms and applications of plant growth promotingrhizobacteria: Current perspective. Journal of King Saud University Science. 26: 1-20.

Ameur, H. and Ghoul, M. (2012). Screening of Actinomycetes Producing Antibacterial Substances and Indole Acetic Acid (IAA) and Optimization of Growth and IAA Production Conditions in Streptomyces sp. SF5.International Journal of Pharmaceutical \& Biological Archives. 3(3):545-551.

Argyris, J., Dahal, P., Hayashi, E., Still, D.W. and Bradford, K.J. (2008). Genetic variation for Lettuce seed thermo inhibition is associated with temperature-sensitive expression of abscisic acid, gibberellin, and ethylene biosynthesis, 
metabolism, and response genes. Plant Physiology. 148: 926-947.

Bashan Y. (1998). Inoculants of plant growth promoting rhizobacteria for use in agriculture. Advance Biotechnology 16:729-770.

Bhattacharyya, P.N. and Jha, D.K. (2012). Plant growth-promoting rhizobacteria (PGPR): emergence in agriculture. Journal of Microbiology Biotechnology. 28:1327-1350.

Bianco C. and Defez R. (2010). Improvement of phosphate solubilization and Medicago plant yield by an Indole-3- acetic acid overproducing strain of Sinorhizobium meliloti. Applied Environmental Microbiology. 76(14): 4626-4632.

Buddhika, U.V.A., Seneviratne, G. and Abayasekara, C.L. (2014). Fungal-bacterial biofilms differ from bacterial monocultures in seed germination and Indole Acetic acid production. International Journal of Scientific and Research Publications. 4(1):1-5.

Dashti, N., Zhang, F., Hynes, R. and Smith, D.L. (1997). Application of plant growth-promoting rhizobacteria to soybean (Glycine max [L.] Merr.) increases protein and dry matter yield under shortseasonConditions Plant and Soil. 188:33-41.

Dragicevic, I., Konjevic, R., Vinterhalter, B., Vinterhalter, D. and Neskovic, M. (2008). The effects of IAA and tetcyclacis on tuberizationin potato (Solanumtuberosum L.) shoot cultures in vitro. Plant Growth Regulation. 54: 189-193.

Franche, C., Lindström, K. and Elmerich, C. (2012). Nitrogen-fixing bacteria associated with leguminous and non-leguminous plants. Plant Soil. 321:35-59.

Glick, B.R., Cheng, Z., Czarny, J. and Duan, J. (2007). Promotion of plant growth by ACC deaminase-producingsoil bacteria. European Journal of Plant Pathology. 119:329-39.

Harmey, M.A., Crowley, M.P., Clinch, P.E.M. (1966). The effect of growth regulators on tuberization of cultured stem pieces of Solanum tuberosum. European Potato Journa.l 9:146-151.

Hayat, R., Ali, S., Amara, U., Khalid, R. and Ahmed, I. (2010). Soil beneficial bacteria and their role in plant growth promotion. Annual Review of Microbiology. 60: 579-598.

Husen, E. (2003). Screening of soil bacteria for plant growth promotion activities in vitro. Indonesian Journal of Agriculture Science 4(1): 27-31.

Khan, Z. and Doty, S.L. (2009). Characterization of bacterial endophytes of sweet potato plants. Plant Soil. 322(2) 197-207.

Kloepper, J.W. (1997). Current status and future trends in Biocontrol Research and Development in the US. International symposium on clean agriculture, Sapporo, DECD, 49-52.

Koomnok, C., Teaumroong, N., Rerkasem, B., Lumyong, S. (2007). Diazotrophendophytic bacteria in cultivated and wild rice in Thailand. Science Asia. 33: 429-435.
Kumar, A., Devi, S., Patil, S., Payal, C. and Negi, S. (2012). Isolation, screening and characterization of bacteria from rhizospheric soils for different plant growth promotion (PGP) activities: an in vitro study. Recent Research in Science and Technology. 4(1): 01-05.

Martínez-Viveros, O., Jorquera, M.A., Crowley, D.E., Gajardo, G. and Mora, M.L. (2010). Mechanisms and practical considerations involved in plant growth promotion by rhizobacteria. Journal of Soil Science and Plant Nutrition. 10: 293-319.

Mia, M.A.B., Shamsuddin, Z.H. and Mahmood M. (2012). Effects of rhizobia and plant growth promoting bacteria inoculation on germination and seedling vigor of lowland rice. African Journal of Biotechnology. 11(16): 3758-3765.

Ngoma, L., Babalola, O. O. and Ahmad, F. (2012). Ecophysiology of plant growth promoting bacteria. Scientific Research and Essays. 7(47): 4003-4013.

Nookaraju, A., Kappachery, S., Yu, J.W., Park, S.W. (2011). Rhizobacteria influence potato tuberization through enhancing lipoxygenase activity. American Journal of Potato Research. 88:441-449.

Patten, C.L. and Glick, B.R. (1996). Bacterial biosynthesis ofindole-3-acetic acid. Canadian Journal of Microbiology. 42: 207-220.

Piromyou, P., Buranabanyat, B., Tantasawat, P., Tittabutr, P., Boonkerd, N. and Teaumroong, N. (2011). Effect of plant growth promoting rhizobacteria (PGPR) inoculation on microbial community structure in rhizosphere of forage corn cultivated in Thailand. European Journal of Soil Biology. 47:44-54.

Saharan, BS and Nehra, V. (2011). Plant Growth Promoting Rhizobacteria: A Critical Review. Life Sciences and Medicine Research 21: 1-30.

Seneviratne, G., Zavahir, J.S., Bandara, W.M.M.S. and Weerasekara, M.L.M.A.W. (2008). Fungalbacterial biofilms: their development for novel biotechnological applications. World Journal of Microbiology and Biotechnology. 24(6): 739-743.

Shahab, S., Ahmed, N. and Khan, N. S. (2009). Indole acetic acid production and enhanced plant growth promotion by indigenous PSBs. African Journal of Agricultural Research. 4 (11):1312-1316.

Sloger, C. and Berkum, P.V. (1988). Endogenous Ethylene Production Is a Potential Problem in the Measurement of Nitrogenase Activity Associated with Excised Corn and Sorghum Roots'. Plant Physiology. 88: 115-118.

Sturz, A.V. (1995). The role of endophytic bacteria during seed piece decay and potato tuberization. Plant and Soil. 175: 257-263.

Suslow, T.V., Kloepper, J.W., Schroth, M.N., Burr, T.J. (1979). Beneficial bacteria enhance plant growth. California Agriculture. 15-17.

Tissue, D.T., Megonigal, J.P. and Thomas, R.B. (1997). Nitrogenase activity and N2 fixation are 
stimulated by elevated $\mathrm{CO} 2$ in a tropical N2-fixing tree. Oecologia. 109:28-33.

Van Loon, L.C. (2007). Plant responses to plant growth-promoting rhizobacteria. European Journal of Plant Pathology. 119(3):243-254.

Vessey, J.K. (2003). Plant growth promoting rhizobacteria as biofertilisers. Plant Soil 255: 571586.

Vrany, J. and Fiker, A. (1984) Growth and yield of potato plants inoculated with rhizosphere bacteria. Folia Microbiology. 29: 248-253.

Xie, H. and Pasternak, J.J., Glick B.R. (1996). Isolation and characterization of mutants of the plant growth-promoting rhizobacterium Pseudomonas putida GR12-2 that overproduce indoleacetic acid. Current Microbiology. 32:6771.
Walpola, B.C and Yoon, M. (2012). Prospectus of phosphate solubilizing microorganisms and phosphorus availability in agricultural soils: A review. African Journal of Microbiology Research. 6(37): 6600-6605.

Yasmin, F., Othman, R., Sijam, K., Saad, M.S. (2009). Characterization of beneficial properties of plant growth-promoting rhizobacteria isolated from sweet potato rhizosphere. African Journal of Microbiology Research. 3(11): 815-821.

Zahir, Z.A., Arshad, M., Frankenberger, W.T. (2004). Plant growth promoting rhizobacteria: applications and perspectives in agriculture. Advances in Agronomy. 81:97-168. 
